\title{
AVALIAÇÃO DA RESISTÊNCIA À COMPRESSÃO DO CONCRETO: COMPARATIVO ENTRE CORPO DE PROVAS DE MOLDADOS E TESTEMUNHOS EXTRAÍDOS
}

\section{EVALUATION OF THE COMPRESSIVE STRENGTH OF THE CONCRETE: COMPARATIVE BETWEEN BODY OF EVIDENCE OF MOLDINGS AND EXTRACTED TESTIMONIES}

Recebido em: 30/10/2018.

Aceito em: 23/11/2018.

\author{
Henrique Jorge Nery de Lima ${ }^{1}$ \\ Rodrigo Lacerda da Silva ${ }^{2}$ \\ Júnior Marques da Silva ${ }^{3}$ \\ Guilherme Sales Soares de Azevedo Melo ${ }^{4}$
}

\section{RESUMO}

Este trabalho apresenta uma avaliação comparativa da resistência mecânica do concreto, entre corpos de provas moldados e testemunhos extraídos de lajes de concreto armado, em um canteiro de obras na região administrativa de Santa Maria- DF, no ano de 2017. O objetivo principal do estudo é identificar e mensurar as variações de resistência à compressão, que ocorrem durante o processo de execução de estruturas de concreto. Serão realizados ensaios à compressão, e logo após, comparadas as principais diferenças entre os corpos de provas, (amostras moldadas), e dos testemunhos extraídos. O concreto que será utilizado nesse estudo será fornecido por central dosadora, com resistência característica de projeto de $25 \mathrm{MPa}$ e $20 \mathrm{MPa}$, fator água/cimento, a/c $\leq 0,6$. Com base nos resultados alcançados neste estudo, conclui-se que a uma redução de aproximadamente $17 \%$ da resistência à compressão dos testemunhos, se comparados ao $\boldsymbol{f}_{\boldsymbol{c k}}$ de projeto em ambos os casos.

Palavras-chave: Resistência à compressão. Corpo de prova. Testemunho.

\footnotetext{
1 Mestre em Estruturas e Construção Civil pela Universidade de Brasília (UnB). Docente do Centro Universitário do Distrito Federal (UDF) e professor substituto da Universidade de Brasília (UnB). E-mail: henrique.lima@udf.edu.br

2 Graduado em Engenharia Civil pelo Centro Universitário do Distrito Federal (UDF). E-mail: drigao719@gmail.com

3 Graduado em Engenharia Civil pelo Centro Universitário do Distrito Federal (UDF). E-mail: juninhojmsmarques@gmail.com

4 Doutor em Estruturas de Concreto pela Polytechnic of Central London (Inglaterra). Docente da Universidade de Brasília (UnB). E-mail: melog@unb.br
} 


\section{ABSTRACT}

This work presents a comparative evaluation of the mechanical strength of concrete, between molded test bodies and testimonies extracted from the slab of concrete armed, at a construction site in the administrative region of Santa Maria-DF, in the year 2017.The order to Identify and measure the variations of compressive strength that occur during the process of execution of concrete structures. Compressive tensile tests will be performed, and soon after, the main differences between the specimens (molded samples), and the extracted samples will be compared. The concrete that will be used in this study will be supplied by central metering unit C25 e C2O, water / cement factor, a / $\mathrm{c} \leq 0,6$. The results obtained in this study point to a reduction of approximately $17 \%$ in the samples compared to $\boldsymbol{f}_{\boldsymbol{c} \boldsymbol{k}}$ the project in both cases, It is also noted that the corrections suggested by the standart ABNT NBR 7680-1:2015 does not contribute to the improvement of resistance indices.

Keywords: Compressive strength. Body of evidence. A testimony.

\section{INTRODUÇÃO}

O controle da resistência à compressão do concreto é parte integrante da construção, sendo indispensável à comprovação da resistência efetiva real. Avaliar se o que está sendo produzido corresponde ao que foi adotado previamente, por ocasião do dimensionamento da estrutura, faz parte da própria concepção do processo construtivo como um todo (HELENE \& TERZIAN, 1993).

Na maior parte das obras, o processo de controle colabora para que a resistência estimada seja similar ou superior ao valor especificado. Todavia, surgem situações com dúvidas sobre a resistência mecânica e a capacidade de carga de um elemento de concreto. Nesses casos é preciso revisar os resultados de ensaios e, se necessário, adotar procedimentos adicionais para investigar qual a resistência efetiva da estrutura (SILVA FILHO \& HELENE, 2011).

Dentro desta proposta, esta pesquisa busca propor melhorias no processo de análise e interpretação dos resultados obtidos através dos ensaios de extração de testemunhos em estruturas de concreto acabadas, bem como mudanças na norma ABNT NBR 7680-1:2015, expondo a necessidade de se avaliar os parâmetros de correção propostos pela norma, e os agentes que podem influenciar nos resultados. Neste contexto a pesquisa tem como principal motivação analisar o comportamento do concreto aplicado em estruturas acabadas, manifestando a importância de corrigir os principais fatores que podem interferir na resistência do concreto, e na busca por inovações que possam contribuir de alguma maneira para a melhoria dos processos de analise em estruturas acabadas da construção civil em nosso país. 


\section{REVISÃO BIBLIOGRÁFICA}

\section{RESISTÊNCIA EFETIVA DO CONCRETO}

A produção do concreto consiste em uma série de atividades controladas e organizadas entre si, podendo o resultado final ser interferido durante o processo de execução entre uma atividade e outra por ato de ação humana e ou mecânica, como a dosagem, mistura, transporte, lançamento, adensamento e cura. Contudo, existem casos em que a qualidade do concreto é posta em dúvida no que diz respeito à resistência do concreto aplicado na estrutura, evidenciando a necessidade de uma investigação das suas propriedades mecânicas (SILVA FILHO \& HELENE, 2011).

A determinação da resistência efetiva é feita através de ensaios em estruturas acabadas, enquanto a resistência potencial é obtida pela ruptura de corpos de provas padrão moldados e ensaiados em condições normalizadas. Pelo exposto, verifica-se que um maior conhecimento da resistência efetiva, bem como a adoção de sistemas de controle de qualidade na execução de estruturas de concreto armado, pode contribuir para um melhor entendimento e ajuste dos coeficientes de minoração adotados a princípio (CREMONINI, 1994).

Na figura 2.1 é apresentado um fluxograma com as principais etapas de produção do concreto:

Figura 2: Significado da resistência à compressão obtida através do controle do concreto

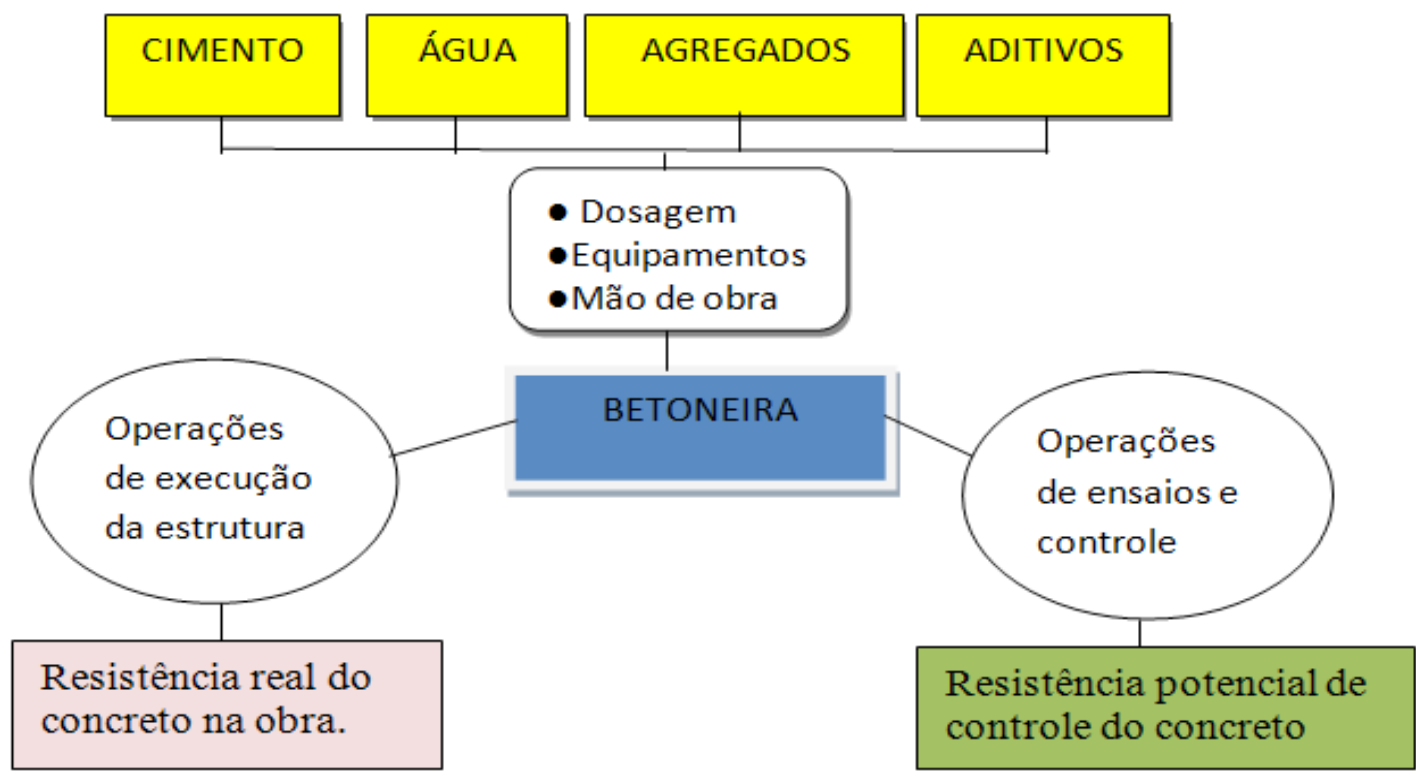

Fonte: Adaptado de (PACHECO \& HELENE). 
A representação da figura 2.1 ilustra a resistência real do concreto que foi utilizado na obra e a resistência potencial, representada através dos corpos de provas moldados e mantidos em condições ideais até o dia do rompimento, e a resistência real através dos testemunhos que necessita de maior atenção, impondo uma análise mais criteriosa na definição da resistência real da obra, dada as características do concreto utilizado nas edificações e porventura à extração de testemunhos.

Por essa razão, o julgamento da resistência do concreto a partir de testemunhos extraídos diretamente da estrutura é uma atividade ainda mais complexa que o exame dos resultados obtidos de corpos de provas moldados. Trata-se de um técnico especializado, e que requer rigor nas operações de amostragem e nos ensaios, assim como experiência e bom senso na avaliação dos resultados obtidos, que são afetados pelas operações de extração e construção (HELENE, et al, 2015)

\section{PARTE EXPERIMENTAL}

A pesquisa consiste basicamente em coletar amostras do concreto utilizado para a confecção de lajes armadas, através de corpos de provas cilíndricos moldados e padronizados com dimensões em centímetros de (10x20) conforme ABNT NBR 5738, bem como amostras de testemunhos extraídos da laje com dimensão predominante de 10 centímetros de altura e $75 \mathrm{~mm}$ de diâmetro. O planejamento dos dias de moldagem dos corpos de prova e elaboração de uma planilha com as datas de concretagem e rompimento, que será estimada aos 7, 14 e 28 dias. Extração e preparo dos testemunhos no canteiro de obras a partir da data de execução do concreto na peça estrutural, com o auxílio de sonda rotativa HILTI, modelo DD 160, Rompimento dos corpos-de-prova: em instalações laboratoriais com equipamento classe 1 ou similar, indicador digital da carga aplicada de acordo com a ABNT NBR 5739/07 e ABNT NBR 7680/15.

Figura 2: Vista da laje concretada

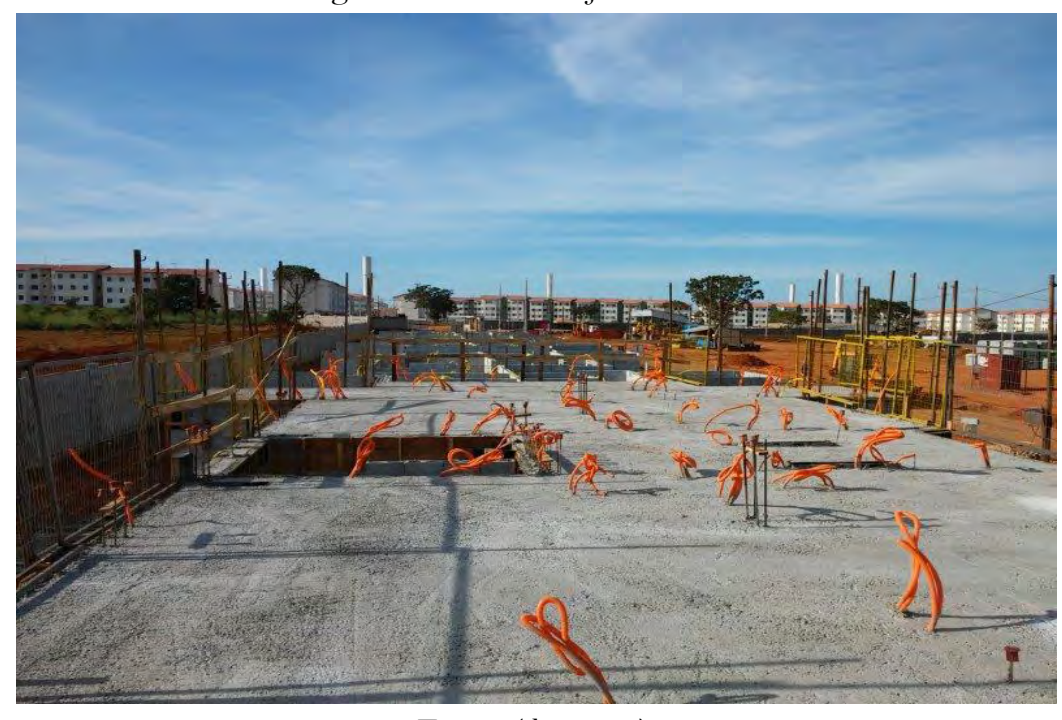

Fonte: (do autor). 
Figura 3: Instrumentos para controle de qualidade no canteiro de obras

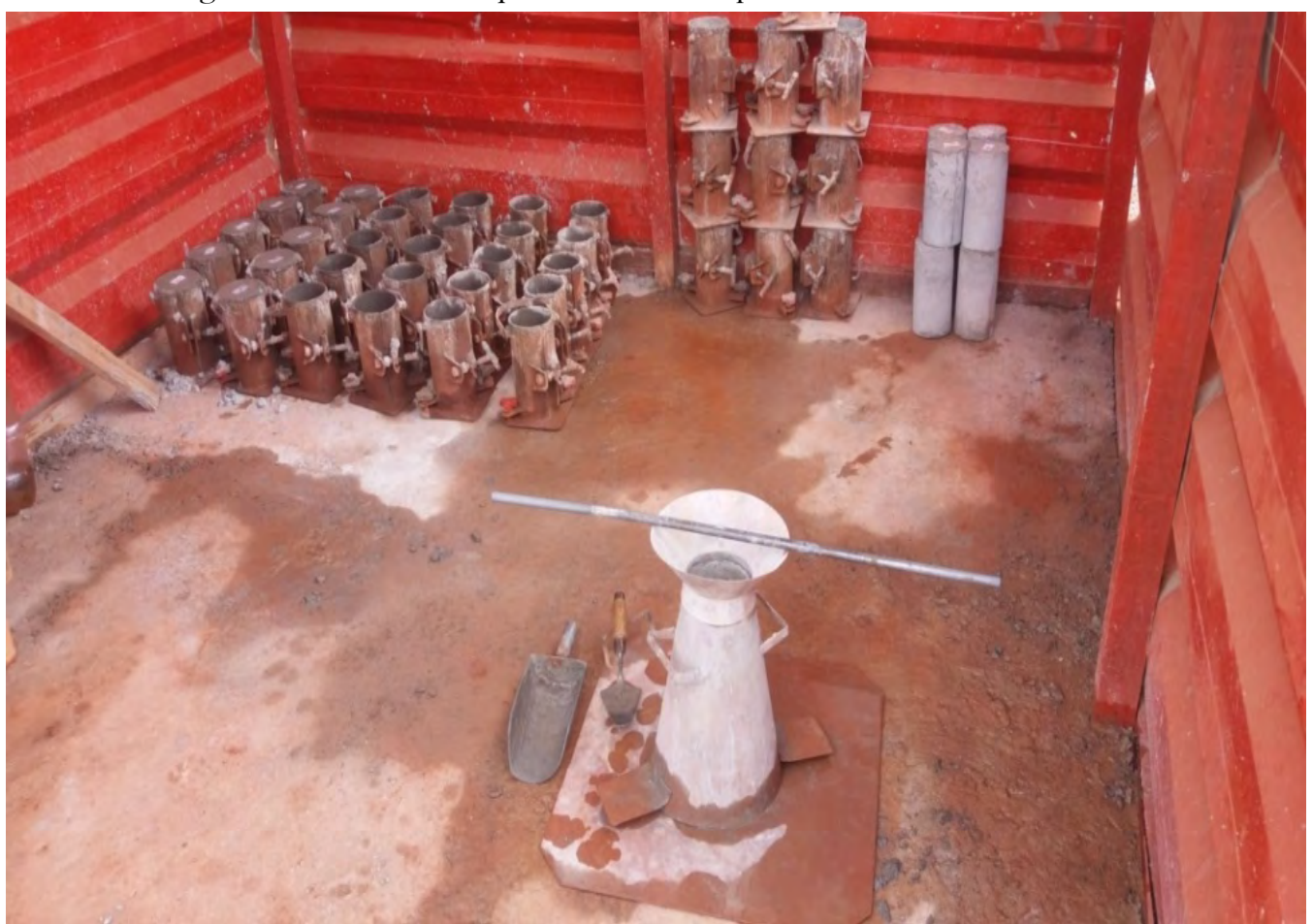

Fonte: (do autor).

Figura 4: Extração dos testemunhos

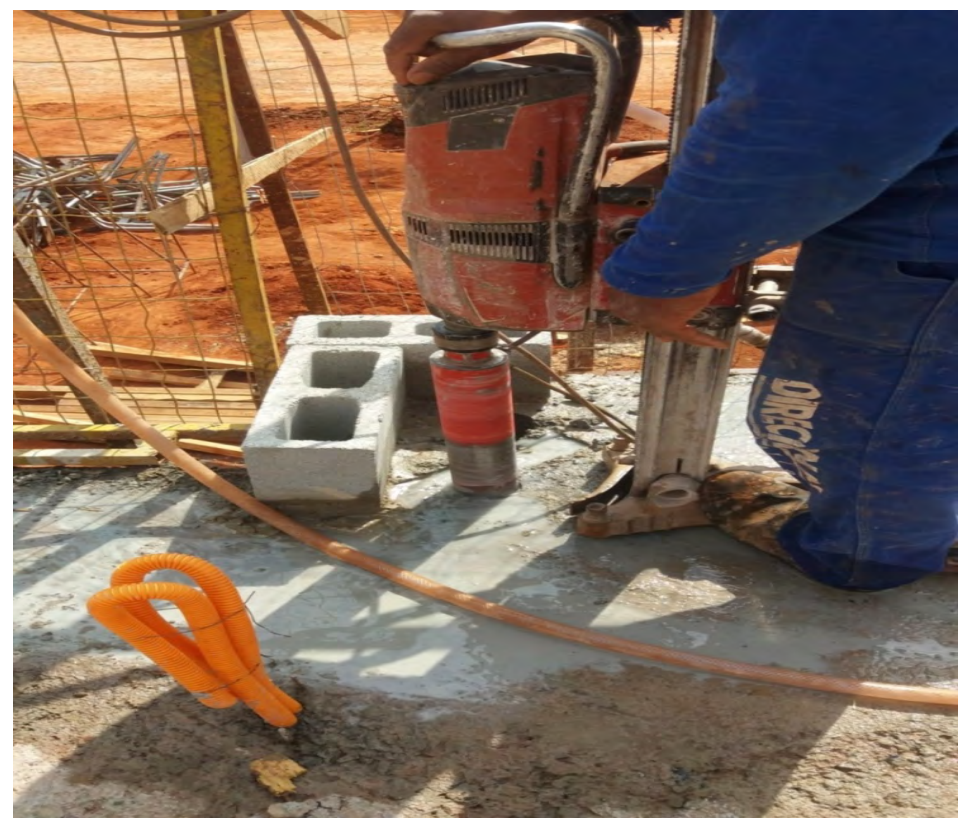

Fonte: (do autor).

Conforme indicado em norma, na expressão utilizada para a correção dos valores obtidos na resistência à compressão dos testemunhos, são quatros os itens a serem observados: 
- $K_{1}$ quando o testemunho não atinge uma relação $h / d=2$, os resultados de resistência à compressão devem ser corrigidos conforme quadro abaixo:

Quadro 1: Tabela 2 da norma NBR 7680-1:2015

\begin{tabular}{|l|c|c|c|c|c|c|c|c|c|c|c|c|c|c|c|}
\hline $\mathrm{h} / \mathrm{d}$ & 2,00 & 1,88 & 1,75 & 1,63 & 1,50 & 1,42 & 1,33 & 1,25 & 1,21 & 1,18 & 1,14 & 1,11 & 1,07 & 1,04 & 1,00 \\
\hline & 0,00 & $-0,01$ & $-0,02$ & $-0,03$ & $-0,04$ & $-0,05$ & $-0,06$ & $-0,07$ & $-0,08$ & $-0,09$ & $-0,10$ & $-0,11$ & $-0,12$ & $-0,13$ & $-0,14$ \\
\hline
\end{tabular}

- $\mathrm{K}_{2}$ o efeito de broqueamento deve ser considerado em todos os casos e é maior menor for o diâmetro do testemunho. Para levar em conta o efeito de broqueamento em função do diâmetro do testemunho, emprega-se o coeficiente de correção conforme recomendação da norma ABNT NBR 7680-1: 2015, sendo permitida a interpolação de valores conforme a seguir no Quadro 3.2:

Quadro 2: Tabela 3 da norma NBR 7680-1:2015

\begin{tabular}{|c|c|c|c|c|c|}
\hline Diâmetro do testemunho Ø $\mathrm{mm}$ & $\leq 25$ & $50 \mathrm{a}^{*}$ & 75 & 100 & $\geq 150$ \\
\hline & Não permitido & 0,12 & 0,09 & 0,06 & 0,04 \\
\hline
\end{tabular}

- $\mathrm{K}_{3}$ os testemunhos devem ser extraídos sempre que possível na mesma direção do lançamento do concreto, para extrações realizadas no sentido ortogonal ao lançamento (como pilares, cortinas e paredes moldadas), deve-se admitir um valor da ordem de $=0,05$, já os testemunhos extraídos no mesmo sentido de lançamento como lajes o $=0$.

- $\mathrm{K}_{4}$ as condições de umidade do testemunho no momento do ensaio devem ser corrigidas, se rompido em condições de saturação $=0$, já se testemunhos forem rompidos secos ao ar $=-0,04$.

Para efeito de cálculo a norma ABNT NBR 7680-1: 2015 estabelece os itens de correção a , utilizados na expressão abaixo:

$$
\text { fci, ext }=\left[1+\left(K_{1}+K_{2}+K_{3}+K_{4}\right)\right] \cdot f c i, \text { ext, inicial }
$$

A bibliografia internacional sugere a multiplicação da resistência obtida por um fator multiplicativo descrito pela equação 2 :

$$
f c k, e x t, e q=K_{1} \cdot K_{2} \cdot K_{3} \cdot K_{4} \cdot K_{5} \cdot K_{6} \cdot K_{7} \cdot K_{8} \cdot K_{9} \cdot f c k, e x t, j
$$

A abordagem desses aspectos referentes aos itens de correção entre e tem enorme influência na interpretação dos resultados, desde que se tome uma postura e uma posição de imparcialidade frente aos resultados apresentados, sejam eles satisfatórios ou não. A necessidade de se avaliar tais itens será abordada nos próximos tópicos, sendo 
objeto de pesquisa de vários pesquisadores que atribuem um coeficiente de correção para os demais itens a respeito temos a deficiência de cura do concreto na obra, como é exposto no Quadro 3.3.

Quadro 3: Efeito da natureza da cura sazonamento (UR e temperatura) na resistência do concreto

\begin{tabular}{c|c|c}
\hline Referência & Sazonamento & Coeficiente \\
\hline Cavalera et al (2011) & $>30^{\circ} \mathrm{C}$ & 1,10 \\
\hline Cavalera et al (2011) & $<15^{\circ} \mathrm{C}$ & 1,05 \\
\hline Mehta e Monteiro (2014) & ao ar & 1,60 \\
\hline Concrete Society (1976) & usual de obra & 1,10 \\
\hline Concrete Society (1976) & membrana de cura & 1,15 \\
\hline Battagim et al (2002) & câmara seca & 1,60 \\
\hline U.S. Bureau of Reclamation (1981) & Ao ar & \\
\hline
\end{tabular}

Adaptado de: (Helene; et al; 2015).

Contudo, existe na vasta bibliografia internacional, a exemplo a ACI 214.4R10 e livros texto de concreto, a sugestão do aumento da resistência do testemunho de $5 \%$ a $7 \%$ para cada $1 \%$ a mais de porosidade (volume de vazios) do concreto extraído em relação à porosidade medida no concreto bem adensado do corpo de prova padrão. Isso pressupõe que a porosidade (ASTM C 642) tenha sido medida no corpo de prova moldado e também no testemunho extraído, para permitir a comparação e eventual correção (HELENE, et al, 2015) conforme Quadro 3.4 a seguir.

Quadro 4: Coeficiente de correção segundo teor de ar aprisionado no concreto devido ao adensamento insuficiente (CONCRETE SOCIETY, 1976)

\begin{tabular}{|c|c|}
\hline Porcentagem de ar aprisionado em volume & Fator de correção por deficiência de compactação, \\
\hline 1,0 & 1,08 \\
\hline 1,5 & 1,13 \\
\hline 2,0 & 1,18 \\
\hline 2,5 & 1,23 \\
\hline 3,0 & 1,28 \\
\hline 3,5 & 1,33 \\
\hline
\end{tabular}

Adaptado de: (Helene, et al, 2015).

O coeficiente aborda a correção devida às microfissurações causadas pela retirada precoce de escoramentos. Apesar de não constar na norma ABNT NBR 14391:2004 um prazo para a retirada dos escoramentos, recomenda-se que a mesma deva ocorrer quando o concreto aplicado à estrutura atingir a resistência necessária para suportar o seu peso próprio e as ações externas.

Segundo Helene (2015), quando um elemento sem resistência suficiente passa a suportar cargas de outros elementos estruturais, podem ocorrer deformações não 
previstas, que podem provocar o surgimento de fissuras e microfissuras devido a esta aplicação prematura de esforços, conforme entendimento de (VIERA FILHO, 2008). Assim seria razoável adotar um coeficiente $=1,11$, quando não atendidas as especificações da norma ABNT NBR 14931:2004.

O coeficiente considera que o concreto esteve, até a data do ensaio isento de cargas desenvolvendo a sua resistência de forma livre, conforme (HELENE; et al; 2015). Ainda sobre o referido coeficiente, achou-se conveniente não adotar fatores de correção a respeito, pois considera-se que devido à adoção de um concreto com alta resistência inicial os ganhos de resistência foram expressivos nas primeiras semanas.

Com relação ao coeficiente achou-se conveniente não adotar fatores de correção a respeito, pois considera-se que, devido à adoção de um concreto com alta resistência inicial, os ganhos de resistência foram expressivos nas primeiras semanas.

O efeito Rüsch é atribuído como fator de correção do coeficiente, devido ao efeito das cargas de longa duração. este fator de correção não foi considerado pois seriam necessários maiores estudos com relação à ocorrência de cargas de longa duração sobre a edificação.

\section{RESULTADOS}

Os gráficos 4.1 e 4.2 demonstram a resistência média à compressão para ambos os concretos de 25 e $20 \mathrm{MPa}$ respectivamente.

Gráfico 1: Resistência Média dos corpos de prova e dos testemunhos com concreto de $25 \mathrm{MPa}$

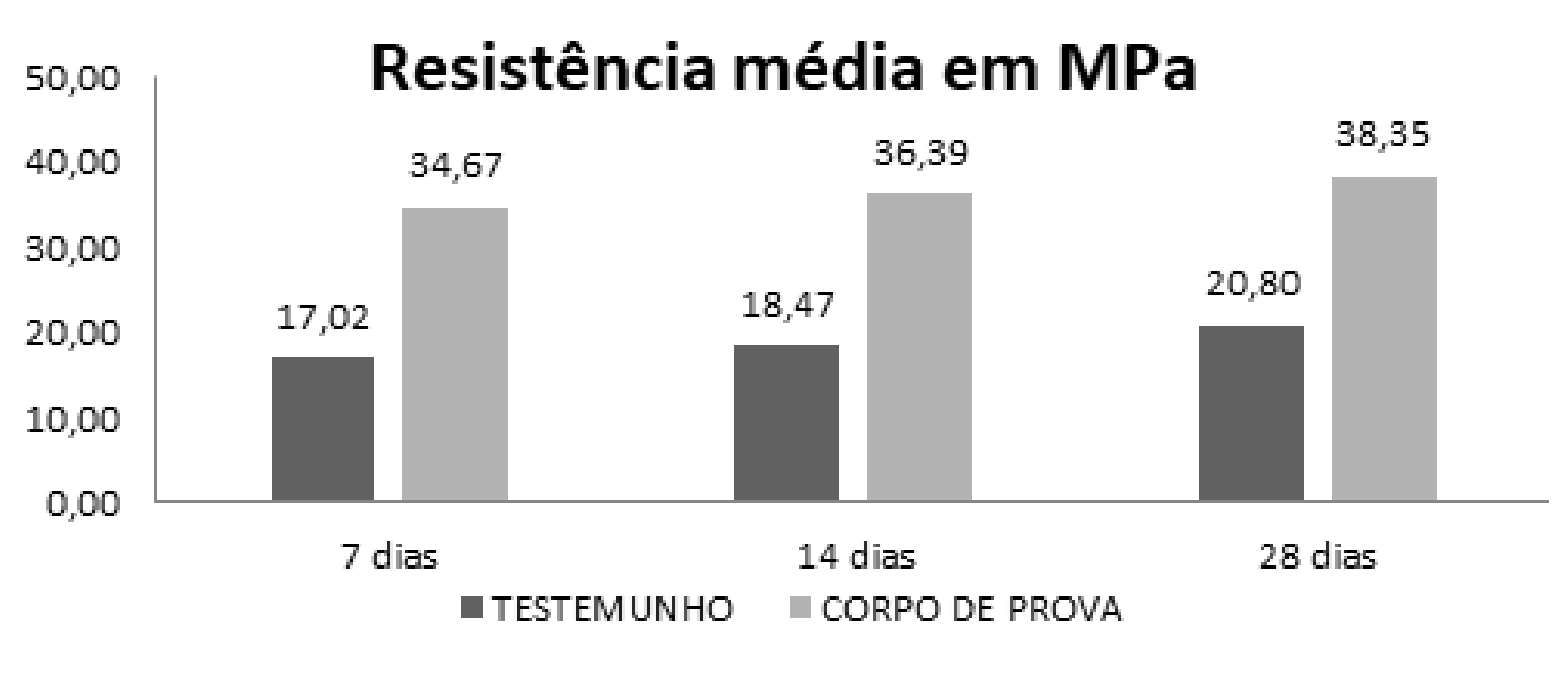


Gráfico 2: Resistência Média dos corpos de prova e dos testemunhos com concreto de $20 \mathrm{MPa}$

\section{Resistência média em MPa}

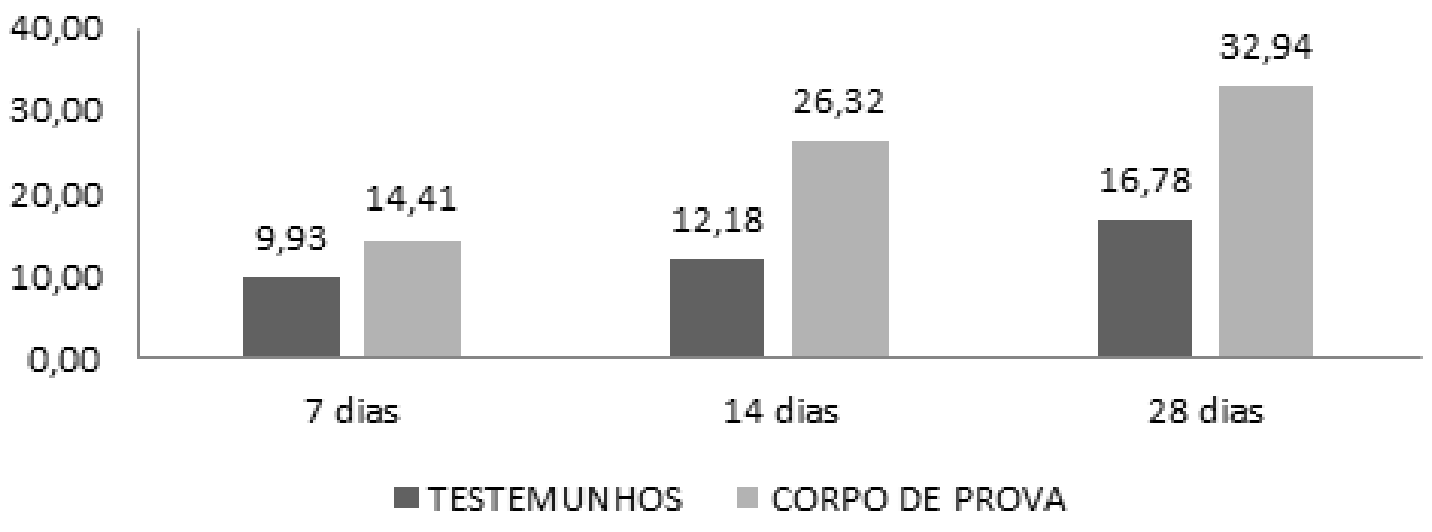

A partir dos resultados apresentados, conclui-se que as resistências dos corpos de provas refletem características de um concreto resistência satisfatória à compressão, contudo os testemunhos que foram extraídos da estrutura com o mesmo concreto e sob certas circunstâncias com as mesmas propriedades em nenhum dos lotes examinados atingiram a resistência do de projeto.

As resistências dos corpos de prova moldados com o concreto classe C25 atingiram uma resistência média de 38,35 MPa aos 28 dias, estando acima do de projeto de $25 \mathrm{MPa}$ esperado, já os testemunhos extraídos atingiram uma resistência média de 20,80 MPa aos 28 dias, ficando abaixo 17,6\% da resistência esperada de $25(\mathrm{MPa})$.

Da mesma forma as resistências dos corpos de provas moldados com o concreto classe C20 atingiram a resistência média de 32,94 $\mathrm{MPa}$ aos 28 dias, ficando acima do de projeto, contudo os testemunhos extraídos atingiram uma resistência média de 16,68 $\mathrm{MPa}$ aos 28 dias, estando 16,60\% abaixo da resistência esperada de projeto de $20 \mathrm{MPa}$.

Observou-se em torno de $17 \%$ de redução da resistência em lajes a partir de testemunhos, ressalta-se que na mesma linha de pesquisa Cremonini (1994), encontrou uma redução de cerca de $20 \%$, da resistência à compressão no concreto aplicado em lajes, evidenciando uma equivalência dos resultados.

No caso dos testemunhos do concreto C20 que foram rompidos aos 28 dias, como foi utilizado o cimento CP II F-40, espera-se um acréscimo de aproximadamente 25\% aos 91 dias conforme tabela de ganhos de resistência em função da relação a/c, ou seja, todas as amostras tendem a atingir o de projeto de $20 \mathrm{MPa}$. Já os testemunhos extraídos das lajes com concreto C25 que tem em sua composição o cimento CP V ARI, tendem a acumular ganhos aos 91 dias cerca de $9 \%$ se comparado a sua resistência aos 28 dias, ficando abaixo dode projeto.

De modo geral a investigação de estruturas acabadas busca sanar as dúvidas atribuídas à resistência do concreto, por meio de ensaios à compressão em testemunhos, que apresentam em sua totalidade deficiências do processo construtivo não se assimilando aos corpos de prova padronizados. Diante do exposto entende-se que para estimar 
a resistência real do concreto, definida a partir da extração de testemunhos, deve-se haver uma alteração dos parâmetros de avaliação, devido a diferença constatada ao se analisar os dados surgidas por causa da interferência de diversos fatores de correção e interpretação das respostas, que podem causar equívocos irreparáveis.

Um fator importante proposto pelas normas é o fator de esbeltez h/d (de acordo com a norma quanto maior esse fator, menor será a resistência do testemunho), porém não foram observados dados relevantes com relação a esse fator, inclusive na literatura. Deve-se, também, atentar para a extração dos testemunhos de modo a não danificar o corpo de prova.

\section{REFERÊNCIAS}

ASSOCIAÇÃO BRASILEIRA DE NORMAS TÉCNICAS. Ensaio de compressão de corpos de provas cilíndricos. Procedimento,NBR 5739 Rio de Janeiro, 2015, 9 páginas

ASSOCIAÇÃO BRASILEIRA DE NORMAS TÉCNICAS. Extração, preparo, ensaio e analise de testemunhos de estruturas de concreto- Procedimento. NBR 7680.Parte 1: Resistência à compressão axial. Rio de Janeiro, 2015, 9 páginas

ASSOCIAÇÃO BRASILEIRA DE NORMAS TÉCNICAS. Preparo, controle, recebimento e aceitação - Procedimento,NBR 12655. Rio de Janeiro, 2015, 29 página.

ASSOCIAÇÃO BRASILEIRA DE NORMAS TÉCNICAS. NBR 5738. Procedimento para moldagem e cura de corpos de prova. Rio de Janeiro, 2015, 9 páginas.

Cremonini, Ruy Alberto. Análise de estruturas acabadas: contribuição para a determinação da relação entre as resistências potencial e efetiva do concreto. São Paulo, 1994. Tese de Doutorado, Escola Politécnica da Universidade de São Paulo.

HELENE, Paulo; CARVALHO, Mariana; COUTO, Douglas; BILESKY, Pedro. Análise crítica do novo texto da ABNT 7680-1:2015.57 Congresso Brasileiro do concreto, IBRACON; Bonito-MS. Volume I: p. $3-13$.

HELENE, Paulo e PACHECO, Jéssika. (2013). Controle da Resistência do Concreto. Mérida- México. Boletim Técnico. 20 páginas. ALCONPAT,

HELENE, Paulo. e TERZIAN, Paulo. Manual de Dosagem e Controle do Concreto. $1^{\circ}$ edição, São Paulo - SP, editora PINI, abril de 1993. 349 p.

ISAIA, Geraldo Cechella (2011). Concreto: Ciência e tecnologia. Análise de estruturas de concreto com problemas de resistência e fissuração. São Paulo- SP IBRACON, Volume 1, p. $1-41$. 